\title{
Shirlee Sharkey: Extraordinary Things Are Possible
}

President and CEO of Saint Elizabeth Health Care Shirlee Sharkey was recently recognized with an Award of Excellence in Nursing Leadership by the Ontario Hospital Association. During the past 13 years that she has led Saint Elizabeth Health Care, Shirlee's leadership has been responsible for the tremendous growth and diversification of Saint Elizabeth Health Care-expanding beyond

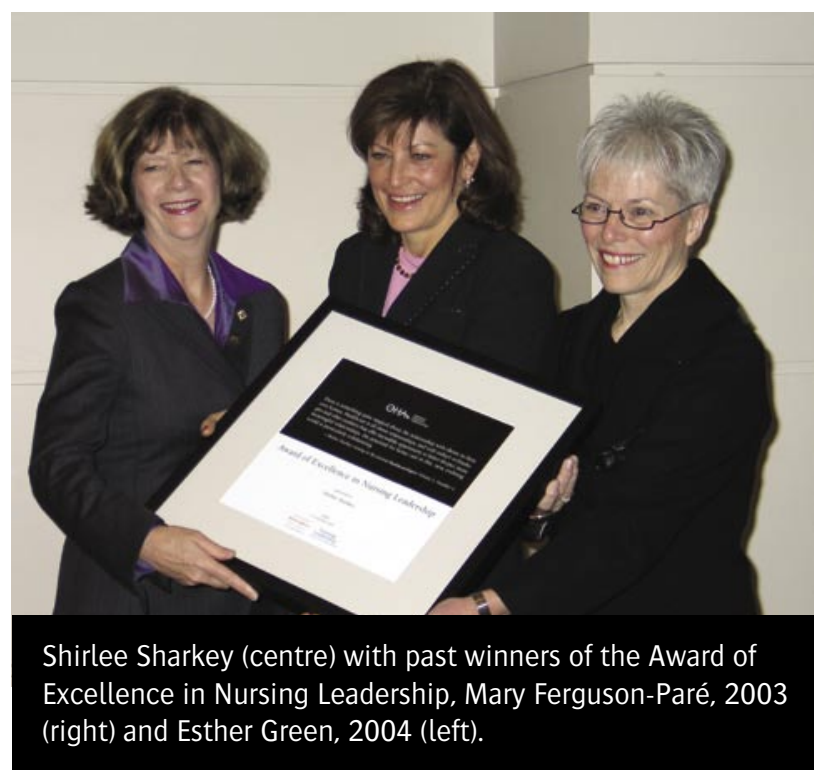
direct client care to share its wealth of talent and wisdom in the areas of consultation, knowledge Toronto and a Director of Ontario's Smart Systems for Health Agency. On exchange and technology solutions, to a national level, she is a Director of support other health organizations and the individuals and families they serve.

Shirlee's leadership is also demonstrated in other ways, as is her commitment to community. Shirlee is the Chair of George Brown College in the Canadian Society for Telehealth and a former president of the Canadian Home Care Association. Internationally, she is Vice Chair of the World Homecare and Hospice Organization. She is also a Past 
President of the Registered Nurses Association of Ontario (RNAO). Academically, Shirlee is crossappointed to the Faculty of Nursing and the Faculty of Medicine

(Department of Health Policy, Management and Evaluation) as an Assistant Professor at the University of Toronto.

\section{What do you perceive to be the most critical characteristics of leadership?}

In the role of CEO, a critical characteristic is to be future-oriented and look at the world through a variety of lenses - first, to identify and push out emerging trends; second, to align key themes with organizational strengths; and third, to be responding proactively before the public explicitly demands it. As leaders, this requires us to step outside the world as we know it and profoundly listen to the people around us. For example, many of the trends we are seeing in healthcare today are the same ones that have fuelled the reinvention of other industries, from banking to retail to telecommunications. So I always try to look at healthcare within this broader context and, in particular, from the public's perspective, because consumers have been and will continue to be a key driver of change.

The perception that leadership gives you more freedom is often an illusion. As leaders, we have a responsibility to a variety of stakeholders who count on us to "do the right thing." At the end of the day, you make the best decisions you can with the information you have. Maintaining strong values and having the courage and conviction to be clear about what they are is vital because they will be tested.

\section{How would you describe your lead- ership style?}

I would say, building a collective wisdom from diverse perspectives. As a leader, I believe in the value of surrounding yourself with people whose skill sets, thinking styles and life experiences are different from your own. In addition to creating a dynamic exchange of ideas, this helps ensure that the outcome will be both responsive and sustainable. It may seem like a no-brainer, but people need to be involved in decisions that affect them. From integration to healthcare renewal, we all need to be thinking about what tomorrow should look like and then trying to influence that within our own role. Leadership is a responsibility that belongs to us all, and when we embrace it as such, extraordinary things are possible.

\section{What skills, developed in nursing, have you been able to apply as CEO?}

As nurses, we all have our own compelling reasons for choosing nursing as our profession, and while our motives are diverse, we share a compassionate spirit and the ability to make a meaningful difference in people's lives. In the early days of my career, I learned the importance of human relationships in creating positive experiences for people. This philosophy has not only guided me throughout my entire career; it continues to be central to my role as CEO. Healthcare is all about 
relationships, and I firmly believe our solutions must be focused on keeping clients and families at the centre and on celebrating and supporting the system's greatest asset-its talent.

\section{Did you plan your career, or has it been spontaneous?}

It's a difficult question to answer in hindsight, but I think it has definitely been a combination of both. Finding the right role in combination with the right work environment is critical. Some people are very fortunate and find it early on, but for most of us, it takes time. We may try out different activities and seize opportunities that we didn't plan. The important thing is to keep striving until you find the experience that is energizing and engaging for you.

\section{What key piece of advice do you offer aspiring leaders?}

I definitely share the view that leadership is an attribute rather than a position or title, and in that sense, I believe we are all aspiring leaders. When I speak with staff and students, I emphasize that leadership manifests [itself] in many different ways. For example, if you have an idea about something that could be done better or differently, put your hand up. Work hard and respect people. When you make a mistake (and we all do), be prepared to learn from it and move on. I often say that a bunch of little mistakes are OK; it's the big ones we want to avoid! Some level of risk-taking and "thoughtful impulsiveness" is strategically necessary to achieve transformative change.

Longwoods HealthcareBoard would like to thank

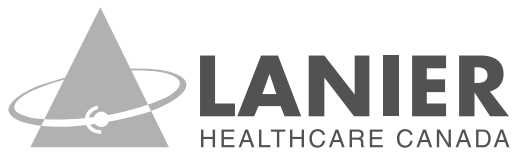

For supporting

Breakfast with the Chiefs

It is a measure of their support for learning. Nothing can be more fundamental to the progress of healthcare.

Longwoods Publishing $\mid$ Enabling Excellence 